\title{
A facile route for the synthesis of novel S-linked 1,3,5-triazine tethered peptidomimetics
}

\author{
Muniyappa Krishnamurthy, Basavaprabhu, K. M. Sharanabai, Vommina V. Sureshbabu* \\ \#109, Peptide Research Laboratory, Department of Studies in Chemistry, Central College Campus, Bangalore University, Dr. B.R. Ambedkar Veedhi, Bangalore 560 001, India
}

\section{A R T I C L E I N F O}

\section{Article history:}

Received 15 May 2014

Revised 18 August 2014

Accepted 19 August 2014

Available online 23 August 2014

\section{Keywords:}

$\mathrm{N}^{\alpha}$-protected amino alkyl isothiouronium

salts

Amino acid ester

Formaldehyde

Dehydrocyclization

\begin{abstract}
A B S T R A C T
An efficient one-pot synthesis of $\mathrm{N}^{\alpha}$-protected S-linked 1,3,5-triazine tethered peptidomimetics is described. The protocol involves a three-component condensation reaction employing $\mathrm{N}^{\alpha}$-protected amino alkyl isothiouronium salt, formaldehyde and amino acid ester or aryl amine as reactants. Various aryl amines with substitutions and amino acids with simple as well as bifunctional side chains were employed to obtain triazine tethered peptidomimetics in good yield.
\end{abstract}

(C) 2014 Published by Elsevier Ltd.
Peptidomimetics have aroused great interest due to their wide utility in developing new therapeutic agents and in drug design. ${ }^{1}$ One of the useful approaches for the synthesis of such peptidomimetics involves the incorporation of heterocyclic units at one or more peptide bonds. In this context, triazoles, tetrazoles, thiazoles, oxazoles, oxadiazoles and many other biologically important heterocycles have been incorporated into the peptide backbone and their biological properties have been studied. ${ }^{2}$

1,3,5-Triazine is an important heterocyclic unit that has found useful applications as antimicrobial and antitumor agents. ${ }^{3}$ It was also used as supramolecular agent, ${ }^{4}$ and in the synthesis of dyes, ${ }^{5}$ as well as DNA cleavage reagent. ${ }^{6}$ Triazine derivatives also showed non-peptidic prokineticin antagonist ${ }^{7}$ and analgesic properties. $^{8}$ The S-linked 1,3,5-triazine derivatives also exhibit a wide range of pharmacological properties. Brown and co-workers ${ }^{9}$ described the synthesis of MAC13243, 1 a new antibacterial compound which inhibits the activity of LolA protein, a crucial component of the lipoprotein targeting pathway in bacteria (Fig. 1). Belonging to the similar class, 5-chlorouracil-linked pyrazolo 1,3,5-triazines, 2 serve as thymidine phosphorylase inhibitor. ${ }^{10}$

In an earlier report, Ralbovsky et al., ${ }^{11}$ described the synthesis of triazinedione through two different methods. In the first method, commercially available sulfonic acid salt of 2-methyl isothiourea was treated with isocyanate in the presence of $\mathrm{NaOH}$ to form an

\footnotetext{
* Corresponding author.

E-mail addresses:

hariccb@gmail.com,

hariccb@hotmail.com,
}

intermediate which was then cyclized using methyl chloroformate and $\mathrm{Et}_{3} \mathrm{~N}$ at $-10^{\circ} \mathrm{C}$ to $\mathrm{rt}$ to obtain the triazinediones. Parallelly, commercially available thiourea was treated with $\mathrm{CH}_{3} \mathrm{Cl}$ in the presence of $\mathrm{MeOH}$ to prepare isothiourea as an intermediate which was then cyclized with $N$-chlorocarbonylisocyanate to yield triazinedione. Kong et al., ${ }^{12}$ reported the synthesis of S-linked 1,3,5-triazine-2,4-diones through cyclization of the intermediate obtained by the reaction of ethoxycarbonylisothiocyanate, methyl
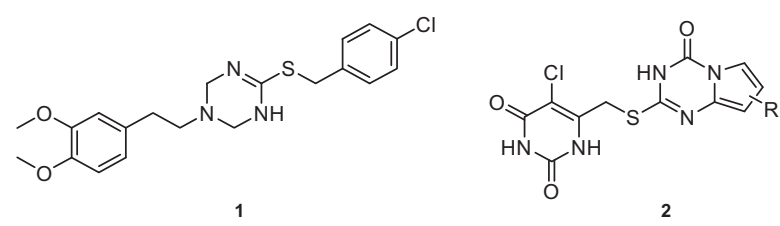

Figure 1. Examples of Biologically active S-linked 1,3,5-triazines.

Table 1

Solvent screening for the synthesis of S-linked 1,3,5- triazine tethered peptidomimetics 5

\begin{tabular}{lll}
\hline Entry & Solvent & Yield (\%) \\
\hline a & THF & 38 \\
b & Acetonitrile & 65 \\
c & EtOH & 40 \\
d & 1,4-Dioxane & 89 \\
e & Methanol & 30 \\
\hline
\end{tabular}




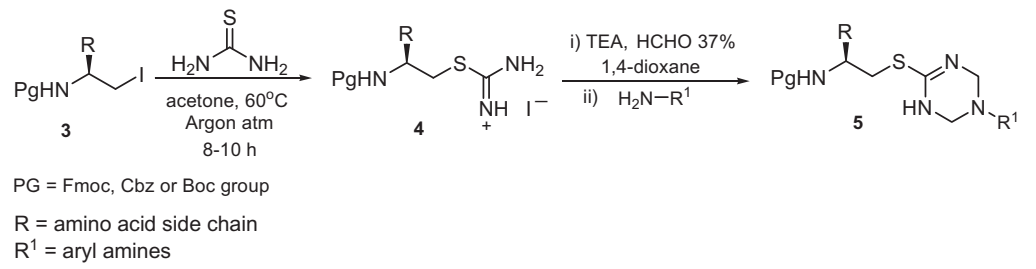

Scheme 1. Synthesis of S-linked 1,3,5-triazine tethered peptidomimetics $\mathbf{5}$.

Table 2

List of S-linked 1,3,5-triazine tethered peptidomimetics $\mathbf{5}$

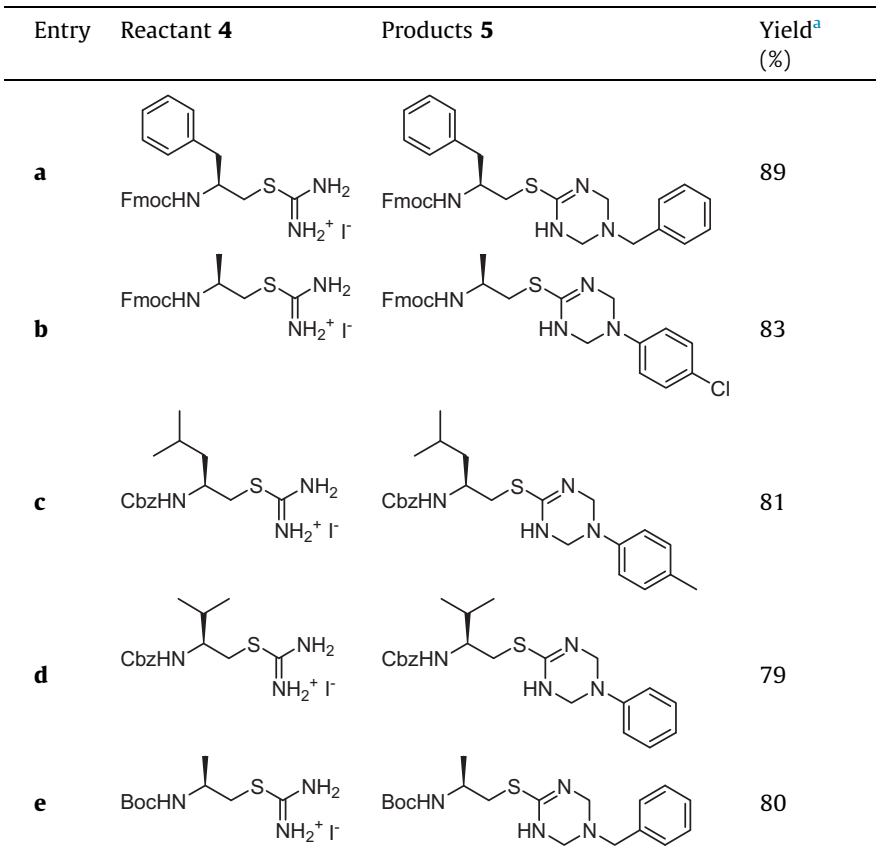

a Yields correspond to the isolated pure S-linked 1,3,5-triazine-tethered peptidomimetics.

amine and benzyl bromide in the presence of $\mathrm{NaH}$ in THF followed by treatment with isocyanate at $60{ }^{\circ} \mathrm{C}$. Lam and co-workers ${ }^{13}$ described the preparation of S-linked triazines using Mukaiyama reagent in the presence of DMAP at about $60-110^{\circ} \mathrm{C}$. These methods inherit certain limitations wherein the isocyanates employed for the reaction are not commercially available and are moisture sensitive and toxic, which otherwise poses difficulty while handling. Also the methods described involve long reaction duration and harsh reaction conditions. Zhao et al. ${ }^{14}$ reported the synthesis of $\mathrm{N}^{\alpha}$-Cbz-amino acyl derived 3,5,6-trisubstituted 1,2,4-triazines using Cbz-protected amino acyl hydrazides and 1,2-diones in the presence of excess $\mathrm{NH}_{4} \mathrm{OAc}$ at $180^{\circ} \mathrm{C}$.

Our group reported several new classes of peptidomimetics possessing heterocycles such as $1,3,4$, -oxadiazole, ${ }^{15} 1,2,4$,-oxadiazole, ${ }^{16} 1,3,4$, -thiadiazole, ${ }^{17}$ triazoles ${ }^{18}$ and tetrazoles. ${ }^{19}$ This list also includes Fmoc-protected amino alkyl S/Se-linked tetrazoles ${ }^{20}$ and Z/Boc-protected S-linked oxadiazole tethered peptidomimetics. ${ }^{21}$ Thus, with the continuing interest in designing heterocycle tethered peptidomimetics we envisaged the synthesis of the S-linked 1,3,5-triazine moiety incorporated into the peptide backbone.

The starting material, $\mathrm{N}^{\alpha}$-protected amino alkyl isothiouronium salt 4 required for the present study was prepared through the literature protocol as reported earlier by our group. ${ }^{22}$ The $\mathrm{N}^{\alpha}$-protected amino acid was subjected to reduction and then to Mitsunobu conditions to form iodo compound. Thus obtained iodo compound was then treated with thiourea in acetone under argon atmosphere at reflux temperature for about $8-10 \mathrm{~h}$ to obtain corresponding isothiouronium salt, which was used as such for the next step.

In an initial study, isothiouronium salt derived from Fmoc-Phe$\mathrm{OH}$, that is, Fmoc-Phe- $\psi\left[\mathrm{CH}_{2}-\mathrm{SC}(\mathrm{NH}) \mathrm{NH}_{2} \cdot \mathrm{HI}\right]$ 4a was made to react with formaldehyde (37 wt \% solution in water) and benzylamine as a test case in the presence of TEA in THF at rt. The product 5a was obtained albeit in very low yield. The four solvents viz acetonitrile, $\mathrm{EtOH}, 1,4$-dioxane and $\mathrm{MeOH}$ (Table 1 ) were screened in parallel reactions. An impressive yield of $89 \%$ of $\mathbf{5 a}$ was isolated when the reaction was carried out using 1,4-dioxane as solvent, in the presence of 1.5 equiv of TEA, 2.0 equiv of $\mathrm{HCHO}, 1.5$ equiv of amine and 1.0 equiv of isothiouronium salt (Scheme 1 ).

With the optimized reaction conditions in hand, the generality of the present protocol was tested by using aryl amines which afforded the title molecules in good yield (Table 2). A plausible reaction mechanism was proposed for the formation of compound 5 (Scheme 2).

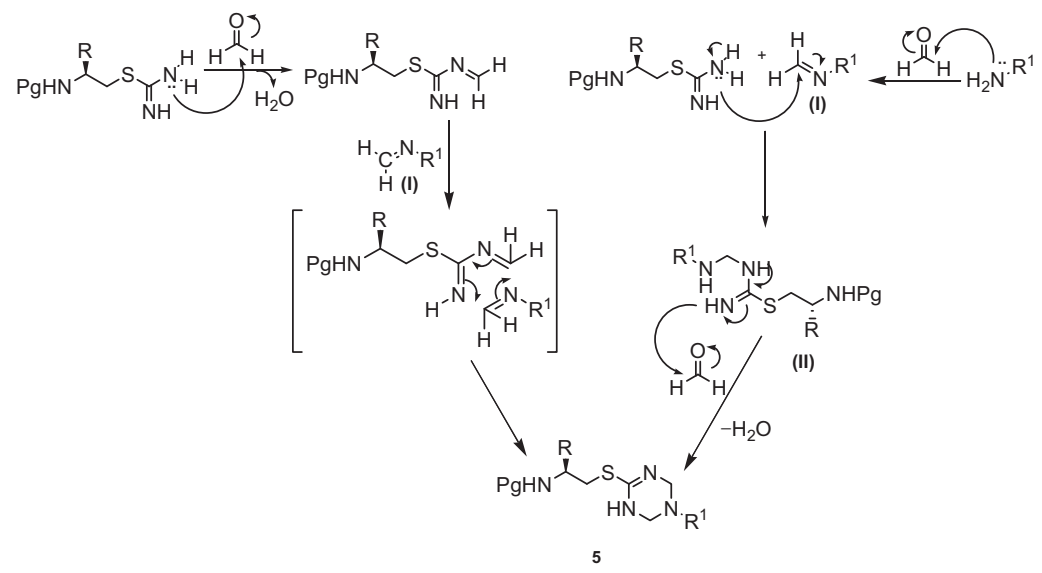

Scheme 2. Plausible pathways for the formation of $\mathrm{N}^{\alpha}$-protected S-linked 1,3,5-triazine tethered peptidomimetics $\mathbf{5}$. 


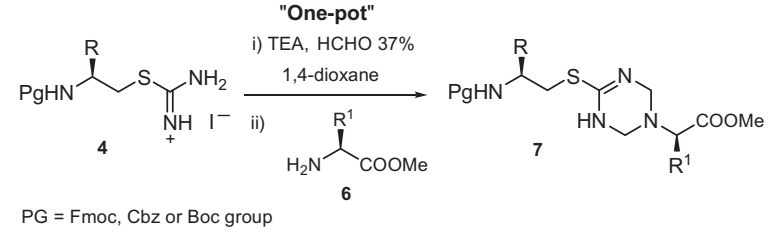

$P G=F m o c$, Cbz or Boc group

$\mathrm{R}, \mathrm{R}^{1}=$ amino acid side chain

Scheme 3. Synthesis of $\mathrm{N}^{\alpha}$-protected S-linked 1,3,5-triazine tethered dipeptidomimetics 7.
In the first step of the reaction, the amine was condensed with formaldehyde producing an imine intermediate [I], which subsequently reacts with a molecule of N-protected amino alkyl isothiourea, giving an intermediate [II]. This intermediate [II] in the presence of formaldehyde undergoes dehydrocyclization to form $\mathrm{N}^{\alpha}$-protected S-linked 1,3,5-triazine tethered peptidomimetics. The formation of the desired product can also be explained through another possible pathway wherein deprotonated isothiouronium salt reacts with $\mathrm{HCHO}$ to give the corresponding imine-like diunsaturated intermediate. This will then react with the intermediate

Table 3

List of $\mathrm{N}^{\alpha}$-protected S-linked 1,3,5-triazine tethered dipeptidomimetics 7

\begin{tabular}{|c|c|c|c|}
\hline Entry & Reactant 4 & Products 7 & Yield (\%) \\
\hline $\mathbf{a}$ & & & 81 \\
\hline b & & & 80 \\
\hline c & & & 83 \\
\hline d & & & 85 \\
\hline $\mathbf{e}$ & & & 82 \\
\hline f & & & 76 \\
\hline g & & & 72 \\
\hline h & & & 79 \\
\hline i & & & 75 \\
\hline
\end{tabular}


(I) in an aza-Diels Alder like process to afford the product $\mathbf{5}$ as illustrated in Scheme 2.

In the next part of the study, we focused our attention towards the synthesis of dipeptidomimetics containing S-linked 1,3,5-triazines. In a typical experiment, Fmoc-Phe- $\psi\left[\mathrm{CH}_{2}-\mathrm{SC}(\mathrm{NH}) \mathrm{NH}_{2} \cdot \mathrm{HI}\right]$ 4d in 1,4-dioxane was treated with $\mathrm{HCHO}$ (37\% wt, in solution of water), TEA and followed by the addition of a solution of H-LeuOMe (deprotonation of $\mathrm{HCl} \cdot \mathrm{H}$-Leu-OMe was carried out using zinc dust) in 1,4-dioxane. The reaction mixture was initially heated until the turbid solution turns into a clear solution. Then it is stirred at $\mathrm{rt}$ for about $6 \mathrm{~h}$ and the completion of the reaction was monitored through TLC. A simple work-up resulted in the corresponding product 7d. The crude product was then purified through column chromatography using $\mathrm{CHCl}_{3}$ and $\mathrm{MeOH}$ as eluent (95:5) to afford the pure product in $85 \%$ yield (Scheme 3 ). The efficacy of this protocol was demonstrated by the synthesis of a series of compounds employing several $\mathrm{N}^{\alpha}$-protected amino alkyl isothiouronium salts and amino acid methyl esters in moderate to good yields (Table 3). ${ }^{23}$ All the compounds were isolated as stable ones and characterized through mass, ${ }^{1} \mathrm{H}$ and ${ }^{13} \mathrm{C}$ NMR analyses. ${ }^{24}$

The possibility of racemization, if any, during the synthesis of $\mathrm{S}$ linked 1,3,5-triazine tethered peptidomimetics via the present protocol was assessed through RP-HPLC analysis of the intentionally made diastereomers, that is, Fmoc-L-Phg-triazine-(R)-PEA $\mathbf{5 f}$ and Fmoc-L-Phg-triazine-(S)-PEA 5g. ${ }^{25}$ From these results it was found that the protocol was racemization-free and yielded optically pure products.

In the present Letter, we have demonstrated an application of $\mathrm{N}^{\alpha}$-protected amino alkyl isothiouronium salts as precursor units for the preparation of S-linked 1,3,5-triazine tethered peptidomimetics in one pot. The synthetic protocol implemented was straightforward, mild and avoids the usage of isothiocyanates used in earlier reports, which were albeit toxic and hazardous and handling of such molecules is difficult. The products were obtained in good yields and characterized by mass, ${ }^{1} \mathrm{H}$ and ${ }^{13} \mathrm{C}$ analyses.

\section{Acknowledgements}

We are thankful to the Board of Research in Nuclear Sciences (BRNS) Grant No. 2011/37C/35/BRNS/1775 Government of India, Mumbai for financial support. BP thanks the CSIR for SRF. We also thank one of the unknown reviewers for suggesting another possible mechanism for the formation of desired product.

\section{Supplementary data}

Supplementary data associated with this article can be found, in the online version, at http://dx.doi.org/10.1016/j.tetlet.2014.08. 075 .

\section{References and notes}

1. (a) Farmer, P. S. In Drug Design; Ariens, E. J., Ed.; Academic Press: San Diego, 1980; Vol. 10, pp 119-143; (b) Farmer, P. S.; Ariens, E. J. Trends Pharmacol. Sci. $1982,3,362-365$

2. (a) Abel, A. D. Lett. Pept. Sci. 2002, 8, 267-272; (b) Welsch, M. E.; Snyder, S. A.; Stockwe, B. R. Curr. Opin. Chem. Biol. 2010, 14, 347-361; (c) Kharb, R.; Rana, M.; Sharma, P. C.; Yar, M. S. J. Chem. Pharm. Res. 2011, 3, 173-186; (d) Kim, S. J.; Lin, C. C.; Pan, C. M.; Rananaware, D. P.; Ramsey, D. M.; McAlpine, S. R. Med. Chem. Comm. 2013, 4, 406-410; (e) Mann, E.; Kessler, H. Org. Lett. 2003, 5, 4567-4570; (f) Banerjee, S.; Ganguly, S.; Sen, K. K. J. Adv. Pharm. Educ. Res. 2013, 3, 494-511; (g) Pedersen, D. S.; Abell, A. Eur. J. Org. Chem. 2011, 2399-2411; (h) Angell, Y. L: Burgess, K. Chem. Soc. Rev. 2007, 36, 1674-1689; (i) Boeglin, D.; Cantel, S.; Heitz, A.; Martinez, J.; Fehrentz, J. A. Org. Lett. 2003, 5, 4465-4468; (j) Niu, T. F.; Wen-bin, Yi L.; Cai, C. ACS Comb. Sci. 2012, 14, 309-328; (k) Yu, K. L.; Johnson, R. L. J. Org. Chem. 1987, 52, 2051-2059; (1) Ko, E.; Liu, J.; Perez, L. M.; Lu, G. G.; Schaefer, A.; Burgess, K. J. Am. Chem. Soc. 2011, 133, 462-477.

3. (a) Zhou, C.; Min, J.; Liu, Z.; Young, A.; Deshazer, H.; Gao, T.; Chang, Y. T. Kallenbach, N. R. Bioorg. Med. Chem. Lett. 2008, 18, 1308-1311; (b) Srinivas, K.;
Srinivas, U.; Bhanuprakash, K.; Harakishore, K.; Murthy, U. S. N.; Rao, V. J. J. Med. Chem. 2006, 41, 1240-1246; (c) Paquin, I.; Raeppel, S.; Leit, S.; Gaudette, F.; Zhou, N.; Moradei, O.; Saavedra, O.; Bernstein, N.; Raeppel, F.; Bouchain, G.; Frechette, S.; Woo, S. H.; Vaisburg, A.; Fournel, M.; Kalita, A.; Robe, M. F.; Lu, A.; Trachy-Bourget, M. C.; Yan, P. T.; Liu, J.; Rahil, J.; MacLeod, A. R.; Besterman, J. M.; Li, Z.; Delorme, D. Bioorg. Med. Chem. Lett. 2008, 18, 1067-1071; (d) Zheng, M.; Xu, C.; Ma, J.; Sun, Y.; Du, F.; Liu, H.; Lin, L.; Li, C.; Ding, J.; Chen, K.; Jiang, H. Bioorg. Med. Chem. 2007, 15, 1815-1827; (e) Mandal, S.; Berube, G.; Asselin, E.; Mohammad, I.; Richardson, V. J.: Gupta, A.; Pramanik, S. K.; Williams, A. L.; Mandal, S. K. Bioorg. Med. Chem. Lett. 2007, 17, 4955-4960.

4. (a) Seki, T.; Yagai, Y.; Karatsu, T.; Kitamura, A. J. Org. Chem. 2008, 73, 33283335; (b) Whitesides, G. M.; Simanek, E. E.; Mathias, J. P.; Seto, C. T.; Chin, D.; Mammen, M.; Gordon, D. M. Acc. Chem. Res. 1995, 28, 37-44; (c) Zerkowski, J. A.; Seto, C. T.; Whitesides, G. M. J. Am. Chem. Soc. 1992, 114, 5473-5475.

5. Um, S. I.; Kang, Y.; Lee, J. K. Dyes Pigm. 2007, 75, 681-686.

6. Chen, J.; Wang, X.; Shao, Y.; Zhu, J.; Zhu, Y.; Li, Y.; Xu, Q.; Guo, Z. Inorg. Chem. 2007, 46, 3306-3312.

7. Coats, S. J.; Dyatkin, A. B.; He, W.; Lisko, J.; Ralbovsky, J. L.; Schultz, M. J.; Patent WO 2006104713, 2006

8. (a) Brown, E. D. Eur. Pat. Appl. EP 300756, 1979.; (b) Balboni, G.; Lazzari, I.; Trapella, C.; Negri, L.; Lattanzi, R.; Giannini, E.; Nicotra, A.; Melchiorri, P.; Visentin, S.; Nuccio, C. D.; Salvador, S. J. Med. Chem. 2008, 51, 7635-7639.

9. Pathania, R.; Zlitni, S.; Barker, C.; Das, R.; Gerritsma, D. A.; Lebert, J.; Awuah, E. Melacini, G.; Capretta, F. A.; Brown, E. D. Nat. Chem. Biol. 2009, 5, 849-856.

10. Sun, L.; Li, J.; Bera, H.; Dolzhenko, A. V.; Chiu, G. N. C. Eur. J. Med. Chem. 2013, 70, $400-410$

11. Ralbovsky, J. L.; Lisko, J. G.; Palmer, J. M.; Mabus, J.; Chevalier, K. M.; Schulz, M. J.; Dyatkin, A. B.; Miskowski, T. A.; Coats, S. J.; Hornby, P.; Wei, H. Bioorg. Med. Chem. Lett. 2009, 19, 2661-2663.

12. Kong, K. H.; Tan, C. K.; Lam, Y. J. Comb. Chem. 2009, 11, 1050-1060.

13. Kong, K. H.; Tan, C. K.; Lin, X.; Lam, Y. Chem. Eur. J. 2012, 18, 1476-1486.

14. Zhao, Z.; Leister, W. H.; Strauss, K. A.; Wisnoski, D. D.; Lindsley, C. W Tetrahedron Lett. 2003, 44, 1123-1127.

15. (a) Prabhu, G.; Sureshbabu, V. V. Tetrahedron Lett. 2012, 53, 4232-4234; (b) Lamani, R. S.; Nagendra, G.; Sureshbabu, V. V. Tetrahedron Lett. 2010, 51, 47054709.

16. Sureshbabu, V. V.; Hemantha, H. P.; Naik, S. A. Tetrahedron Lett. 2008, 49, 5133 5136.

17. Nagendra, G.; Ravi, S. L.; Narendra, N.; Sureshbabu, V. V. Tetrahedron Lett. 2010 $51,6338-6341$.

18. (a) Narendra, N.; Vishwanatha, T. M.; Sureshbabu, V. V. Int. J. Pept. Res. Ther 2010, 16, 283-290; (b) Sureshbabu, V. V.; Narendra, N.; Hemantha, H. P. Protein Pept. Lett. 2010, 17, 499-506.

19. Sureshbabu, V. V.; Venkataramanarao, R.; Naik, S. A.; Chennakrishnareddy, G. Tetrahedron Lett. 2007, 48, 7038-7041.

20. Sureshbabu, V. V.; Vasantha, B.; Hemantha, H. P. Synthesis 2011, 9, 1447-1455.

21. Sureshbabu, V. V.; Vasantha, B.; Nagendra, G. Tetrahedron Lett. 2012, 53, 1332 1336.

22. Sureshbabu, V. V.; Vishwanatha, T. M.; Vasantha, B. Synlett 2010, 1037-1042.

23. General procedure for the synthesis of compounds (5a-e) and (7a-7i)

To a solution of isothiouronium salt, 4 (1 equiv), TEA (1.5 equiv) and $\mathrm{HCHO}$ ( 2.0 equiv, $37 \mathrm{wt} \%$ solution in water) in 1,4-dioxane was added a solution of aryl amine or amino acid methyl ester (1.5 equiv, deprotonation of hydrochloride salt of amino acid ester was carried out using zinc dust). The reaction mixture was heated to reflux to obtain a clear solution. It was allowed to stir for about $6 \mathrm{~h}$ at room temperature. After the completion of the reaction as indicated by TLC analysis, the reaction mixture was diluted with water $(50 \mathrm{~mL})$ and extracted into ethyl acetate $(3 \times 15 \mathrm{~mL})$. The combined organic extracts were then washed with $5 \% \mathrm{HCl}$, water and brine solution, dried over anhydrous $\mathrm{Na}_{2} \mathrm{SO}_{4}$ and evaporated in vacuo. The crude product was purified through silica gel column chromatography (100-200 mesh) using $\mathrm{CHCl}_{3} / \mathrm{MeOH}$ (95:5) as eluent.

24. Characterization data for selected compounds $\mathbf{5 a - e}$ and $\mathbf{7 a - i}$ Spectroscopic data for compound (5a): ${ }^{1} \mathrm{H}$ NMR $\left(400 \mathrm{MHz}, \mathrm{CDCl}_{3}\right): \delta 2.52(\mathrm{~s}, 2 \mathrm{H})$, $2.89(\mathrm{~s}, 4 \mathrm{H}), 2.92(\mathrm{~s}, 2 \mathrm{H}), 3.48-3.56(\mathrm{~m}, 2 \mathrm{H}), 3.98-4.02(\mathrm{~m}, 1 \mathrm{H}), 4.14-4.18(\mathrm{~m}$, $1 \mathrm{H}), 4.44-4.46(\mathrm{~m}, 2 \mathrm{H}), 5.09(\mathrm{br} \mathrm{s}, 1 \mathrm{H}), 5.36(\mathrm{br} \mathrm{s}, 1 \mathrm{H}), 7.16-7.73(\mathrm{~m}, 18 \mathrm{H}) ;{ }^{13} \mathrm{C}$ NMR $\left(100 \mathrm{MHz}_{\mathrm{CDCl}}\right): \delta 29.8,40.5,47.0,52.9,54.6,58.0,65.4,67.1,125.2$, $125.5,126.0,126.2,126.3,126.4,126.5,127.3,128.2,128.4,128.7,128.9,132.1$ $132.5,134.8,135.6,136.1,138.1,142.9,153.1,155.8$ ppm; ESI-MS: $m / z[M+H]^{+}$ calcd for $\mathrm{C}_{34} \mathrm{H}_{34} \mathrm{~N}_{4} \mathrm{O}_{2} \mathrm{~S}$ : 563.24; found: 563.20 .

Spectroscopic data for compound (7a): ${ }^{1} \mathrm{H}$ NMR $\left(400 \mathrm{MHz}, \mathrm{CDCl}_{3}\right): \delta 1.56(\mathrm{~d}$, $J=7.0 \mathrm{~Hz}, 3 \mathrm{H}), 2.68(\mathrm{~s}, 2 \mathrm{H}), 3.10(\mathrm{~s}, 4 \mathrm{H}), 3.52-3.55(\mathrm{~m}, 2 \mathrm{H}), 3.62(\mathrm{~s}, 3 \mathrm{H}), 3.70-$ $3.81(\mathrm{~m}, 1 \mathrm{H}), 4.12-4.30(\mathrm{~m}, 1 \mathrm{H}), 4.32(\mathrm{t}, J=6.6 \mathrm{~Hz}, 1 \mathrm{H}), 4.47(\mathrm{~d}, J=6.4 \mathrm{~Hz}, 2 \mathrm{H})$, 5.55 (br s, 1H), 5.69 (br s, $1 \mathrm{H}), 6.97-7.68(\mathrm{~m}, 13 \mathrm{H}) ;{ }^{13} \mathrm{C}$ NMR $\left(100 \mathrm{MHz}, \mathrm{CDCl}_{3}\right)$ : $\delta 18.9,31.9,33.7,47.8,49.7,50.8,58.1,59.0,61.9,64.1,125.0,125.5,126.0$, $126.2,126.5,126.5,127.5,127.8,128.6,128.6,130.8,132.1,132.8,134.9,135.9$ 138.7, 141.0, 152.9, 156.0, 171.5 ppm; ESI-MS: $\mathrm{m} / \mathrm{z}[\mathrm{M}+\mathrm{H}]^{+}$calcd for $\mathrm{C}_{31} \mathrm{H}_{34} \mathrm{~N}_{4} \mathrm{O}_{2} \mathrm{~S}$ : 559. 23; found: 559.20 .

25. Racemisation study: The RP-HPLC analysis of the pure products $\mathbf{5 f}$ and $\mathbf{5 g}$ showed single peaks at different $R_{t}$ values, that is, at $R_{t}=16.16$ and $16.94 \mathrm{~min}$, respectively. These studies showed that the prepared compounds, $\mathbf{5 f}$ and $\mathbf{5 g}$ contain a single optically pure isomer and consequently it was proved that the present protocol was free from racemization. (Method for RP-HPLC analysis: Gradient $0.1 \%$ TFA, acetonitrile $30-100 \%$ in 30 min with a flow rate of $0.5 \mathrm{ml}$ / $\min . \lambda_{\max }=254 \mathrm{~nm}$.) 